Pontificia Universidade Catónicica

Isabela Gomes Bustamante

A produção escrita em inglês como língua estrangeira pela abordagem dos gêneros discursivos

$O$ estudo de um caso

Dissertação de Mestrado

Dissertação apresentada como requisito parcial para obtenção do título de Mestre pelo Programa de PósGraduação em Letras do Departamento de Letras da PUC-Rio.

Orientadora: Profa. Dra. Barbara Jane Wilcox Hemais 


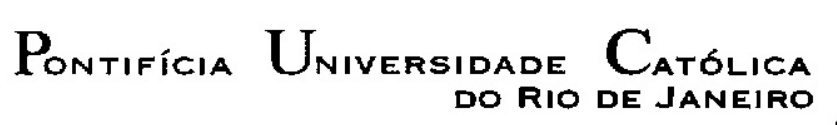

Isabela Gomes Bustamante

\title{
A produção escrita em inglês como língua estrangeira pela abordagem dos gêneros discursivos \\ $O$ estudo de um caso
}

\begin{abstract}
Dissertação apresentada como requisito parcial para obtenção do título de Mestre pelo Programa de PósGraduação em Letras do Departamento de Letras do Centro de Teologia e Ciências Humanas da PUC-Rio. Aprovada pela Comissão Examinadora abaixo assinada.
\end{abstract}

\section{Profa $^{a}$. Dra. Barbara Jane Wilcox Hemais \\ Orientadora Departamento de Letras - PUC-Rio \\ Prof $^{a}$. Dra. Lúcia Pacheco de Oliveira \\ Departamento de Letras - PUC-Rio}

Profa. Dra. Tânia Maria Granja Shepherd

Instituto de Letras - UERJ

Prof. Dr. Paulo Fernando Carneiro de Andrade Coordenador Setorial do Centro de Teologia e Ciências Humanas

- PUC-Rio

Rio de Janeiro, 15 de março de 2007. 
Todos os direitos reservados. É proibida a reprodução total ou parcial do trabalho sem autorização da universidade, da autora e do orientador.

\section{Isabela Gomes Bustamante}

Graduou-se em Letras (Língua Inglesa e Literaturas) pela Universidade do Estado do Rio de Janeiro em 1999. Cursou Especialização em Língua Inglesa na Universidade do Estado do Rio de Janeiro em 2001. Leciona inglês há 12 anos em cursos de idiomas privados e escolas particulares.

Ficha Catalográfica

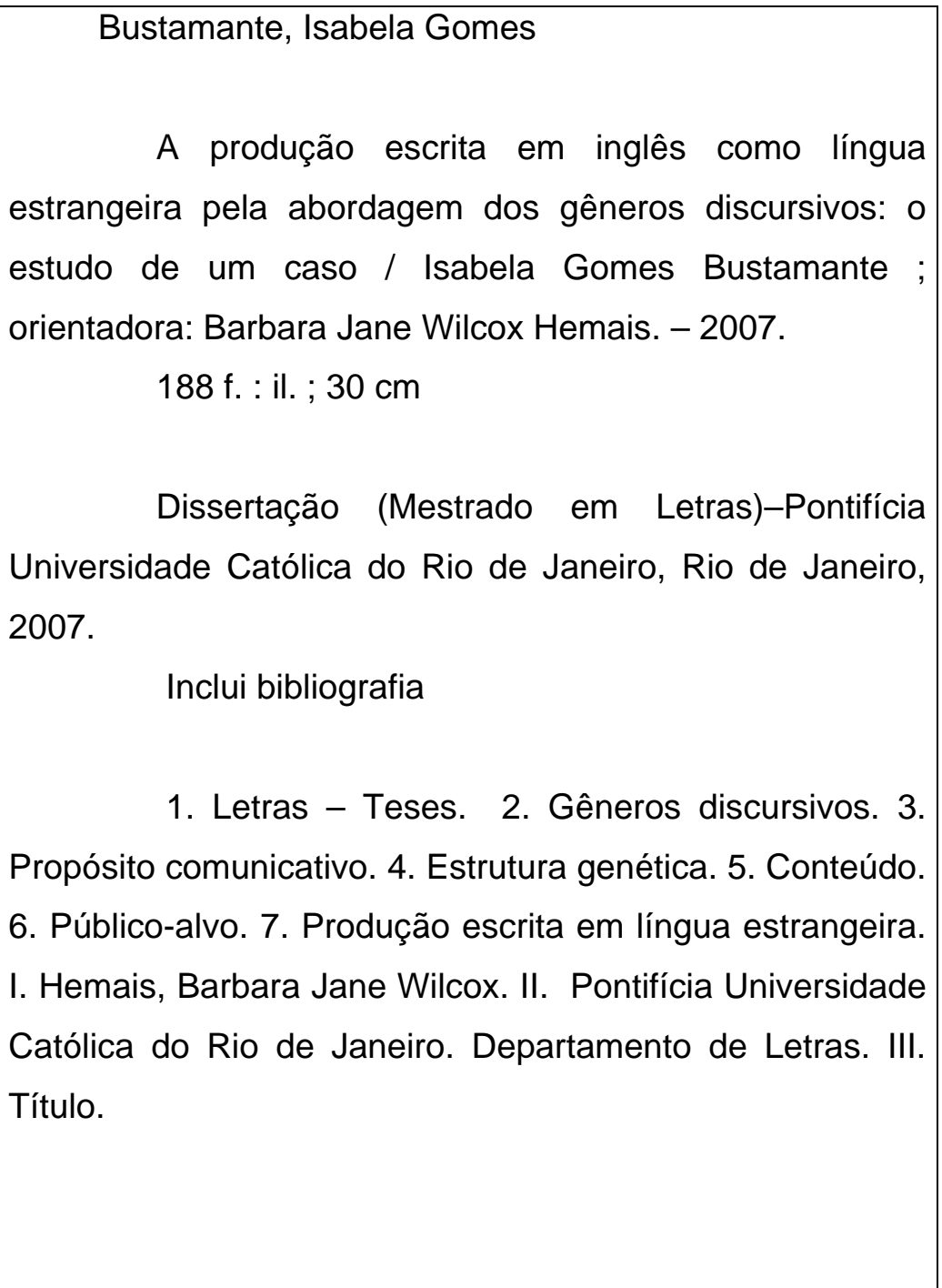

CDD: 400 


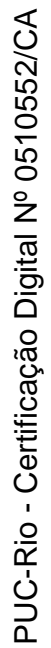

Aos meus pais e ao Lobo, pela paciência e amor. 


\section{Agradecimentos}

À Professora Barbara Jane Wilcox Hemais pela orientação, competência e dedicação.

Às Professoras Tânia Shepherd e Lucia Pacheco por aceitarem fazer parte da Comissão Examinadora.

Aos meus pais, Nadia e Ivan Bustamante, pelo carinho, apoio, estímulo e compreensão da minha ausência ao longo deste último ano.

Ao Lobo, pela sua ilimitada paciência e carinho em todos os momentos e, principalmente, nos momentos mais difíceis deste trabalho.

Aos meus irmãos, Tatiana e Ivan Bustamante, pelo estímulo, mesmo que de longe.

À Chiquinha, secretária de Pós-Graduação do Departamento de Letras, pela gentileza e boa vontade em todos os momentos.

Aos meus colegas de trabalho, Adriana Lima, Alexandre Siqueira, Barbara Melo, Carmen Cruz, Cristina Machado, Fernanda Reis, Lorena Figueiredo, Rodrigo Veloso e Vânia D’Angelo, pela paciência, compreensão e amizade.

À Elisa Borges, Marcia Nogueira e Mônica Souza, colegas de Mestrado na PUC, pela amizade e carinho ao longo do curso.

À Professora Tânia Shepherd, que desde a graduação, na UERJ, me incentivou a dar continuidade aos estudos.

À amiga Olívia Fialho, que foi um exemplo de mestranda e que muito me incentivou.

À amiga Maria Regina Violante, que, através dos seus elogios e críticas, sempre 
esteve presente na minha vida pessoal, profissional e acadêmica.

Aos meus sogros, Vera e Ronaldo Gomes Ferreira, pelo amor e palavras carinhosas em todos os momentos.

A todos os meus ex-alunos que carinhosamente contribuíram para que eu pudesse realizar este trabalho. 


\section{Resumo}

Bustamante, Isabela Gomes; Hemais, Barbara Jane Wilcox. A produção escrita em inglês como língua estrangeira pela abordagem dos gêneros discursivos - O estudo de um caso. Rio de Janeiro, 2007. 188p. Dissertação de Mestrado - Departamento de Letras, Pontifícia Universidade Católica do Rio de Janeiro.

O presente estudo tem por objetivo analisar as redações escritas por alunos brasileiros de uma mesma turma de curso de inglês assim como suas respostas aos questionários e às entrevistas, a fim de investigar, primeiro, as produções escritas como gêneros discursivos e, segundo, as percepções dos alunos acerca dos gêneros discursivos que produziram. Esta análise é feita com base nas cinco características de gêneros propostas por Swales (1990:58): propósito comunicativo, estrutura genérica, estilo, conteúdo e público-alvo. O estudo qualitativo foi feito através da análise de vinte e oito redações escritas por dezesseis alunos de uma mesma turma de nível avançado de curso de inglês sobre dois gêneros distintos e um tipo textual. Foram escritas dez redações sobre o gênero 'carta de conselho', dez sobre 'resenha de filme' e oito narrativas. Após responderem um questionário, cinco alunos desta turma foram entrevistados para que suas respostas pudessem auxiliar o estudo das suas redações à luz da teoria de gêneros discursivos (Swales 1990, 2001). A análise dos dados mostra que os alunos têm conhecimento do propósito comunicativo e do conteúdo dos gêneros que escreveram, no entanto, eles demonstram uma certa falta de domínio da estrutura genérica quando não há um modelo a ser seguido. Esta variação estrutural, contudo, não impede que o evento comunicativo seja bem sucedido, a julgar pelo desempenho dos alunos no curso. Há variação, também, com relação à percepção do público-alvo do texto, sendo que ora o aluno tem em mente um leitor imaginário para o seu texto ora ele escreve para o professor. Tanto as entrevistas quanto as redações demonstraram que uma maior aquisição lexical e revisão de estruturas gramaticais são pertinentes para que o aprendiz escreva com maior fluência e confiança. Os resultados mostram que, apesar dos alunos terem conhecimento dos gêneros que produzem, eles necessitam adquirir maior autonomia no aprendizado para que saibam investigar suas próprias dificuldades e 
possam revisar e consolidar os conteúdos por si mesmos. A pesquisa aponta na direção de uma abordagem pedagógica que estimule os alunos a adquirir maior confiança e fluência ao escrever e produzir os gêneros de forma autônoma, levando-os a uma participação ativa em práticas discursivas em sua vida social, profissional e acadêmica.

\section{Palavras-chave}

Gêneros discursivos, Propósito comunicativo, Estrutura genérica, Conteúdo, Público-alvo, Produção escrita em língua estrangeira. 


\section{Abstract}

Bustamante, Isabela Gomes; Hemais, Barbara Jane Wilcox. Writing in English as a foreign language from a genre-based approach: A case study. Rio de Janeiro, 2007. 188p. Master's Dissertation - Departamento de Letras, Pontifícia Universidade Católica do Rio de Janeiro.

This study analyzes the writing of Brazilian students from one class in a language course as well as their responses to a questionnaire and an interview, in order to investigate genre characteristics in their written work and also their perceptions concerning the genres they produce. The analysis is based on the five characteristics of genres presented by Swales (1990:58): communicative purpose, structure, style, content and audience. This qualitative study used 28 compositions written by 16 students in one advanced-level class in a language course; two genres and one text type were analyzed. The data include 10 advice letters, 10 film reviews, and 8 narratives. After all the students answered the questionnaire, five from the same class were interviewed so that their perceptions could be considered in the genre analysis (Swales 1990, 2001). The analysis of the data showed that the students have some awareness of the communicative purpose and content of the genres they produced; however, they demonstrate a lack of control of genre structure when there is no given model for the writing. This structural variation does not hinder the students' success as learners, though, considering their overall performance in the course. There is also variation in the students' perception of audience, since either they envision an imaginary reader or they write for the teacher. Both the interviews and the texts showed that further lexical learning and review of grammatical structures would help them write more fluently and confidently. The results indicate that, although the students have some genre awareness about their writing, they need to acquire greater learner autonomy in order to be able to investigate their own difficulties and revise and consolidate the content on their own. The study suggests an approach to teaching that will encourage learners to gain more confidence and fluency in their writing and to produce genres with autonomy, so that they may be enabled to participate actively in discourse practices in their social, professional and academic life. 


\section{Key words:}

Genres, Communicative purpose, Genre structure, Content, Audience, Foreign language writing.

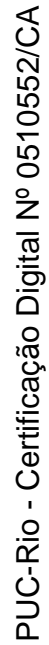




\section{Sumário}

1 Introdução 16

$\begin{array}{ll}\text { 1.1. Histórico } & 16\end{array}$

1.2. Justificativa e relevância da pesquisa 16

1.3. Áreas de pesquisa 21

1.4. Objetivos e perguntas de pesquisa 21

1.5. Estrutura do trabalho 23

2 Fundamentação teórica $\quad 25$

2.1. Questões teóricas de gêneros discursivos 25

2.2. Correntes de estudos de gêneros discursivos 31

2.3. Teorias da escrita 34

2.3.1. Ensino e pesquisa da escrita em inglês 37

2.4. Gêneros discursivos e o ensino da escrita em inglês como língua

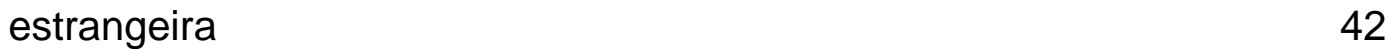

3 Aspectos metodológicos $\quad 49$

3.1. A pesquisa 49

3.2. A coleta de dados 51

3.2.1. Instrumentos de pesquisa 51

3.2.1.1. Os questionários $\quad 51$

3.2.1.2. As entrevistas 52

3.2.1.3. As redações 53

3.2.2. Os participantes $\quad 54$

3.2.3. O local 56

3.3. Tratamento dos dados $\quad 57$

3.3.1. Cópias e tabulação das redações antes da correção 57

3.3.2. Tabulação das respostas ao questionário 58

3.3.3. Transcrições das entrevistas 58

3.4. A análise textual 58 
4 Análise de dados e discussão 61

4.1. Categorias de análise 62

4.2. Narrativa 68

4.2.1. 'Narrativa' segundo a teoria de gêneros 70

4.2.2. A análise 70

4.2.2.1. Propósito do tipo textual 'narrativa' 70

4.2.2.2. Estrutura do tipo textual 'narrativa' 75

4.2.2.3. Conteúdo do tipo textual 'narrativa' 78

4.2.2.4. Público-alvo do tipo textual 'narrativa' 79

4.2.2.5. Escolhas verbais do tipo textual 'narrativa' 80

4.3. Carta de conselho 87

4.3.1. Propósito do gênero 'carta de conselho' 89

4.3.2. A estrutura do gênero 'carta de conselho' 93

4.3.3. Conteúdo do gênero 'carta de conselho' 96

4.3.4. Público-alvo do gênero 'carta de conselho' 97

4.3.5. Escolhas léxico-gramaticais do gênero 'carta de conselho' 98

4.4. Resenha de filme 101

4.4.1. Propósito do gênero 'resenha de filme' 103

4.4.2. Estrutura do gênero 'resenha de filme' 104

4.4.3. Conteúdo do gênero 'resenha de filme' 106

4.4.4. Público-alvo do gênero 'resenha de filme' 108

4.4.5. Escolhas léxico-gramaticais do gênero 'resenha de filme' 109

5 Outras questões pertinentes 113

6 Considerações finais 124

7 Referências bibliográficas $\quad 134$ 


\section{Lista de anexos}

Anexos

Anexo A

Tabulação das respostas aos

143 questionários

Anexos B

Trechos da transcrição com a aluna A. 145

Anexos C

Trechos da transcrição com a aluna T. 146

Anexos D

Trechos da transcrição com a aluna B. 147

Anexos E

Trechos da transcrição com o aluno R. 149

Anexos F

Trechos da transcrição com o aluno P. 151

Anexo G

Tabulação das redações

155

Anexos $\mathrm{H} 1-\mathrm{H} 8$

Redações: Narrativa

156

Anexos I1-I10

Redações: Carta de Conselho

164

Anexos J1-J10

Redações: Resenha de Filme

176

Anexo K

Plano de Aula - $2^{\mathrm{a}}$ semana

186

Anexo L

Plano de Aula - 9a semana

187

Anexo M

Plano de Aula - 10 a semana

188 


\section{Lista de quadros, figuras e gráficos}

Quadro 1 - Redações escritas ao longo do semestre 54

Quadro 2 - Redações que compõem o corpus desta pesquisa 54

Quadro 3 - Descrição dos participantes 55

Quadro 4 - Estrutura genérica da narrativa 75

Quadro 5 - Estratégias de avaliação utilizadas pelos alunos $\quad 77$

Quadro 6 - Ocorrência de tempos verbais da narrativa 84

Quadro 7 - Estrutura genérica da 'carta de conselho' 94

Quadro 8 - $\quad$ Estrutura genérica da 'resenha de filme' 105

Figura 1 - Triangulação dos dados quantitativos e qualitativos $\quad 50$

Gráfico 1 - Ocorrência de tempos verbais da narrativa nas oito 84 redações 


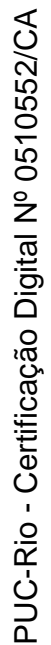

What is written without effort is generally read without pleasure.

Samuel Johnson 